\title{
APOL1, Acidity, and ATP: Affecting Mitochondrial Function
}

\author{
Jeffrey B. Kopp \\ Kidney Diseases Section, NIDDK, NIH, Bethesda, MD, USA
}

In this issue of the American Journal of Nephrology, Li and colleagues [1] report that that an acidic extracellular environment potentiates the effects of APOL1 renal risk allele proteins to compromise cell bioenergetics. APOL1 variants, termed G1 and G2, were identified in 2010 and were shown to increase killing of trypanosomes that had evolved the APOL1 serum resistance protein. These variants are common among African-descent populations, with allele frequencies of up to $50 \%$ in regions of West Africa and $\sim 35 \%$ in the USA and are particularly associated with focal segmental glomerulosclerosis and collapsing glomerulopathy, including HIV-associated nephropathy. Other associations include glomerulosclerosis (historically referred to as either arterionephrosclerosis or hypertension-attributed kidney disease) and preeclampsia and with worse outcomes in lupus nephritis and clinically diagnosed diabetic kidney disease.

In the succeeding decade, a multiplicity of mechanisms has been identified by which these protein variants may compromise eukaryotic cell function, as recently reviewed [2] and as shown in Table 1. APOL1 is expressed in many tissues, most abundantly in the liver, but also in the brain, lung, kidney, gastrointestinal tract, skeletal muscle, adipose tissue, and bone marrow. $\mathrm{Li}$ and colleagues asked an interesting and an important question: why are the pathologic effects of the APOL1 variants manifested predominantly in the kidney? What might the answer to this question tell us about functions of APOL1 or about the intermolecular interactions in which APOL1 might participate?

These authors have addressed a specific hypothesis that a low extracellular $\mathrm{pH}$, unique to the kidney, alters the intracellular effects of APOL1 risk variants. They looked for evidence of mitochondrial dysfunction, as this is an established cause of focal segmental glomerulosclerosis, and APOL1 variants have been previously associated with impaired mitochondrial dysfunction.

The renal interstitium is defined as the intertubular, extra-glomerular, and extravascular renal space, and it manifests several distinctive features. The renal interstitium receives fluid reabsorbed from the tubular lumens by tubular epithelial cells, and the fluid is then returned to the circulation via the peritubular capillaries. The renal interstitial hydrostatic pressure, measuring approximately $5 \mathrm{~mm} \mathrm{Hg}$, is lower than that of other tissues, due to the considerable flow of water from the tubular lumen to the renal interstitium and on to the peritubular capillaries [3, 4]. Medullary oxygen tension is very low, $\sim 10 \mathrm{~mm} \mathrm{Hg}$, due to high oxygen demands of tubular activity and the architecture of the blood supply, with capillaries first supplying glomeruli and proximal tubule before they enter the medulla $[5,6]$. Most important for the current discussion, the renal interstitial $\mathrm{pH}$ is notably lower than the interstitial $\mathrm{pH}$ in other organs. Reported interstitial values measured in rat vasa recta blood were $\mathrm{pH} 5.7$ during anti-diuresis and reached $\mathrm{pH} 4.8$ after $50 \mathrm{~min}$ of furosemide-induced diuresis [7].

The experimental model system that Li and colleagues [1] employed to study APOL1 effects on $\mathrm{pH}$ involved human embryonic kidney-293 cells, which conditionally express each of the APOL1 variants (G0, G1, or G2) in response to doxycycline. These authors found that after $8 \mathrm{~h}$ of activation of APOL1 gene expression, with cells in growth medium at $\mathrm{pH} 6.8, \mathrm{APOL} 1$ risk variant-expressing cells had shorter mitochondria (13\% shorter for the G1 variant and 9\% shorter for the G2 variant) compared to

$\begin{array}{ll}\text { karger@karger.com } & \text { ( ) 2020 Published by S. Karger AG, Basel } \\ \text { www.karger.com/ajn } & \text { This is a work of the U.S. Government and is not subject } \\ \text { to copyright protection in the United States. } & \text { Foreign copyrights may apply. }\end{array}$


Table 1. Effects of APOL1-G1 and APOL1-G2 variants in eukaryotic cells compared to APOL1-G0 common variant

\begin{tabular}{lll}
\hline Inflammation, host response & Altered organelle function & Altered protein function \\
\hline Protein kinase R activation & $\begin{array}{l}\text { Autophagic flux blockage and increased autophagic cell } \\
\text { death }\end{array}$ & $\begin{array}{l}\text { Increased ion channel } \\
\text { permeability }\end{array}$ \\
\hline RIG-1/NFkB-driven inflammation & $\begin{array}{l}\text { Cytoskeletal disorganization (via reduced microRNA- } \\
193 \mathrm{~A})\end{array}$ \\
\hline $\begin{array}{l}\text { Formation of suPAR - integrin } \alpha_{\mathrm{v}} \beta_{3}-\text { APOL1 } \\
\text { tripartite complex }\end{array}$ & $\begin{array}{l}\text { Endolysosomal trafficking, stress, and functional } \\
\text { impairment }\end{array}$ \\
\hline NLRP3 inflammasome activation & \begin{tabular}{l} 
Lysosomal permeability increase \\
\hline
\end{tabular} & Mitochondrial dysfunction \\
\hline
\end{tabular}

Shown are effects of APOL1 renal risk variants in transfected eukaryotic cultured cells (human or mouse), generally expressing APOL1 at higher than physiological levels and possibly at or above pathophysiological levels. NLRP3, NOD (nucleotide-binding oligomerization domain)-like receptor protein 3; suPAR, urokinase-type plasminogen activator receptor.

the G0 cell mitochondria, whereas mitochondrial lengths were similar when cultured at $\mathrm{pH}$ 7.4. Cell viability assessed by release of lactate dehydrogenase was unaffected by the low $\mathrm{pH}$ conditions. Prior work from this group demonstrated that APOL1 kidney risk variants induce mitochondrial fission in human renal tubular cell lines and that effects on mitochondrial dynamics and cell viability were reversible with Mdivi-1, an inhibitor of DRP1 (a member of the dynamin superfamily of mechanochemical GTPases) and therefore of mitochondrial fission [8].

These data suggest that a low tissue $\mathrm{pH}$ might exacerbate APOL1-mediated tubular cell injury. What are the implications of this finding? The authors note the intriguing clinical evidence that a higher dietary acid load might contribute to the higher risk for end-stage kidney disease among African Americans, as this acid load has been linked to albuminuria and reduced glomerular filtration rate in this population [9], although it remains to be es- tablished this is related to the APOL1 genetic variants. Clinical studies will be needed to test the attractive hypothesis that dietary alterations (reduced acid load and/ or base supplements) or the use of thiazide diuretics, which promote proximal tubule bicarbonate reabsorption) [10], might be renoprotective in African Americans with 2 APOL 1 risk alleles and CKD or at particularly increased risk for kidney disease.

\section{Conflict of Interest Statement}

The author has no conflicts of interest to disclose.

\section{Funding Sources}

This work was supported by the Intramural Research Program, NIDDK, NIH.

\section{References}

1 Li DF, Snipes JA, Murea M, Molina AJA, Divers J, Freedman BI, et al. An acidic environment induces APOL1-associated mitochondrial fragmentation. Am J Nephrol. Forthcoming. DOI: /10.1159/000509989.

2 Ma L, Divers J, Freedman BI. Mechanisms of Injury in APOL1-associated kidney disease. Transplantation, 2019;103(3):487-92.

3 Cowley AW Jr. Role of the renal medulla in volume and arterial pressure regulation. Am J Physiol. 1997;273(1 Pt 2):R1-15.

4 Michel CC, Woodcock TE, Curry FE. Understanding and extending the Starling principle. Acta Anaesthesiol Scand. 2020.
5 Epstein FH. Oxygen and renal metabolism. Kidney Int. 1997;51(2):381-5.

6 Pannabecker TL, Layton AT. Targeted delivery of solutes and oxygen in the renal medulla: role of microvessel architecture. Am J Physiol Renal Physiol. 2014;307(6):F649-55.

7 Kersting U, Dantzler DW, Oberleithner H, Silbernagl S. Evidence for an acid $\mathrm{pH}$ in rat renal inner medulla: paired measurements with liquid ion-exchange microelectrodes on collecting ducts and vasa recta. Pflugers Arch. 1994;426(3-4):354-6.
8 Ma L, Ainsworth HC, Snipes JA, Murea M, Choi YA, Langefeld CD, et al . APOL1 kidneyrisk variants induce mitochondrial fission. Kidney Int Rep. 2020;5(6):891-904.

9 Banerjee T, Tucker K, Griswold M, Wyatt SB, Harman J, Young B, et al. Dietary potential renal acid load and risk of albuminuria and reduced kidney function in the Jackson Heart Study. J Ren Nutr. 2018;28(4):251-8.

10 Goraya N, Wesson DE. Novel dietary and pharmacologic approaches for acid-base modulation to preserve kidney function and manage uremia. Curr Opin Nephrol Hypertens. 2020;29(1):39-48. 